\title{
Colorectal Filiform Serrated Adenoma
}

National Cancer Institute

\section{Source}

National Cancer Institute. Colorectal Filiform Serrated Adenoma. NCI Thesaurus. Code C96468.

A traditional serrated adenoma that arises from the colon or rectum. It is characterized by the presence of prominent villous projections of the neoplastic epithelium. 